\title{
TRANSFORMAÇÃO AGRÍCOLA DIGITAL: O ENTRELAÇAMENTO DA AGRICULTURA E TRANSFORMAÇÃO DIGITAL PARA O FUTURO INOVADOR DO SETOR AGRÍCOLA
}

Versão do autor aceita publicada online: 04 mar. 2021

Publicado online: 25 jun. 2021

Como citar esse artigo - American Psychological Association (APA): França, R. de S., Correa, F., Maria, T. C., Ribeiro, J. S. de A. N., \& Ferreira, E. de P. (2021). Transformação agrícola digital: o entrelaçamento da agricultura e transformação digital para o futuro inovador do setor agrícola. Exacta. DOI: https://doi.org/10.5585/exactaep.2021.18745.

\section{Renata de Souza França}

profrenatafranca@gmail.com

https://orcid.org/0000-0002-3809-0975

Universidade Fumec

Universidade do Estado de Minas Gerais

Doutoranda em Sistemas de Informação e Gestão do Conhecimento pela Universidade FUMEC. Mestra em Sistemas de Informação e Gestão do Conhecimento pela FUMEC. Especialista em Gestão Estratégica de Negócios pela PUC - Minas, Gestão de Projetos pela Faculdade Pitágoras e Gestão Educacional, também pela Faculdade Pitágoras. Graduada em Sistemas de Informação pela PUC Minas. Analista de Negócios e Requisitos e Professora Universitária da Universidade do Estado de Minas Gerais.

\section{Fábio Correa}

fabiocontact@gmail.com

http://orcid.org/0000-0002-2346-0187

Universidade FUMEC

Pós-Doutorado pelo Programa de Ciência da Informação da Universidade Federal de Minas Gerais (UFMG). Doutor e Mestre em Sistemas de Informação e Gestão do Conhecimento. Possui MBA em Engenharia de Software e Governança de Tecnologia da Informação e Graduação em Sistemas de Informação. Atuação como Professor do Curso de Ciência da Computação e do Programa de PósGraduação em Sistemas de Informação e Gestão do Conhecimento da Universidade FUMEC. Experiência profissional em consultorias e Projeto de Pesquisa e Desenvolvimento, bem como atuou por 15 anos no mercado de Tecnologia da Informação. Atualmente é professor na Graduação e no Programa de Pós-Graduação em Sistemas de Informação e Gestão do Conhecimento da Universidade FUMEC. Atua na área de Ciência da Computação, com ênfase em Sistemas de Informação, e Ciência da Informação, com ệnfase em Gestão do Conhecimento.

\section{Thaís Campos Maria}

thaiscmariaadv@gmail.com

http://orcid.org/0000-0001-5102-6065

Universidade FUMEC/ IFMG - Campus Congonhas

Doutora em Sistemas de Informação e Gestão do Conhecimento pela Universidade FUMEC; Mestre em Direito Público pela Universidade FUMEC; Assistente em Administração do IFMG - Campus Congonhas.

\author{
Jurema Suely de Araújo Nery Ribeiro \\ jurema.nery@gmail.com \\ http://orcid.org/0000-0002-6465-6020 \\ Universidade Fumec
}


Doutora em Sistemas de Informação e Gestão do Conhecimento. Mestre em Administração - Área de pesquisa: Estratégia e Competitividade. MBA em Logística. MBA em Finanças. MBA em Gestão de Instituições. Especialização em Administração da Produção. Bacharel em Administração. Construiu sua trajetória com experiência de 32 anos, como Gestora nas áreas Administrativa, Planejamento de Controle da Produção, Logística, Almoxarifado, Expedição, Suprimentos em algumas empresas nacionais e multinacionais (Jabil do Brasil, Itambé, ABC Dados, Condor Equipamentos Industriais) com ramos de atividades diversos (Eletroeletrônica, Laticínios e Metalurgia). No Ensino Superior possui sólida experiência de 16 anos atuando como Diretora de Campus, Coordenadora de Pós-graduação e Graduação e Professora universitária em diversas Instituições de Ensino Superior (FUMEC, Newton Paiva, PUC, SENAC, UEMG, UNA). Associada individual da SBGC. Atualmente é Coordenadora do Curso de Administração da Universidade FUMEC e participa do grupo de Pesquisa KM-Inova da Universidade FUMEC, desenvolvendo pesquisas na área da Inovação, Estratégia e Gestão Conhecimento. Diretora Executiva da Capacitar JNR. Consultora Organizacional. Professora Universitária. Orientadora de trabalhos no Stricto Senso e MBA. Autora de Livros e Artigos publicadôs em Revistas e Congressos Nacionais.

\title{
Eric de Paula Ferreira
}

eric.p.f@gmail.com

https://orcid.org/0000-0002-7513-501X

Universidade do Estado de Minas Gerais - UEMG

Bacharel em Sistemas de Informação pela FAI - Centro de Ensino Superior em Gestão, Tecnologia e Educação, pós graduado em Gestão de TI pelo IETEC - Instituto de Educação Tecnológica, MBA em Administração de Projetos com Ênfase em TI pelo IETEC - Instituto de Educação Tecnológica, Mestre em Sistemas de Informação e Gestão do Conhecimento pela Universidade FUMEC e Doutorado em Sistemas de Informação e Gestão do Conhecimento pela Universidade FUMEC. Possui mais de dez anos de experiência na área de desenvolvimento de software, profissional certificado PMP® e tem como interesses de pesquisa as temáticas: Gestão do Conhecimento e da Informação; Gestão de Projetos; Inovação; Startups; Redes de Colaboração e Aprendizagem; Liderança e Gestão de Pessoas; e Transferência de Tecnologia e Conhecimento.

\section{Resumo}

A Transformação Digital insere-se na sociedade do conhecimento e os processos produtivos aliados a intangibilidade do conhecimento assumem maior relevância que os bens tangíveis. A agricultura chega a era digital e se modela a novos caminhos de crescimento e inovação. Essa pesquisa tem como objetivo avaliar, por meio da literatura, a integração das temáticas de Agricultura Digital e Transformação Digital como ferramenta inovadora para o setor agrícola. É uma pesquisa de abordagem qualitativa e caráter exploratório-descritivo. Foram investigados artigos científicos oriundos das bases SCOPUS, CAPES e EMBRAPA. Os resultados apontam que a Agricultura Digital tem sido tratada anterior a Transformação Digital e mediada por termos tecnológicos, ao mesmo tempo que a Transformação Digital traz em seu bojo a premissa de estudos e análises. A condução desta pesquisa em outras bases e a realização de análise dos problemas relacionados à Transformação Digital na Agricultura 4.0 são sugestões de pesquisas futuras.

Palavras Chaves: Transformação Digital. Agricultura. Agrícola. Agricultura Digital.

\begin{abstract}
Digital Transformation inserted in the knowledge society and the production processes combined with the intangibility of knowledge assume greater relevance than tangible goods.
\end{abstract}


Agriculture reaches the digital age and shapes new paths of growth and innovation. This research aims to evaluate, through the literature, the integration of the themes of Digital Agriculture and Digital Transformation as an innovative tool for the agricultural sector. It is research with a quantitative approach and an exploratory-descriptive character. Scientific articles from the SCOPUS, CAPES and EMBRAPA databases were investigated. The results show that Digital Agriculture has been treated before Digital Transformation and mediated by technological terms, at the same time that Digital Transformation brings with it the premise of studies and analyzes. Conducting this research on other bases and conducting an analysis of the problems related to Digital Transformation in Agriculture 4.0 are suggestions for future research.

Keywords: Digital Transformation; Agricultural; Agriculture; Digital Agriculture;

\section{INTRODUÇÃO}

Ao longo da história, as organizações passaram por mudanças. Dentre as eras da sociedade os meios de geração de riqueza ditavam as atividades e os recursos a serem usados na busca do sucesso econômico (Huntington, 1994; Toffler, 1987). Na coeva era da economia digital uma nova lógica guia o saber científico e cria outras maneiras de pensar e de entender a realidade, sendo essas baseadas na estrutura de geração do conhecimento aplicável e utilizável para a solução de problemas concretos (Parra, 2007).

A dinamicidade proposta pelas tecnologias de informação e comunicação adentram setores econômicos e exige novas condutas para alcance de vantagens competitivas. O cenário mercadológico contemporâneo passa a ser representado por disrupturas e inovações (Ito \& Howe, 2016) e, assim como as indústrias, a agricultura faz uso de tecnologias para promover transformações de negócio e se desenvolve agrupando às ações tradicionais, processos automatizados e máquinas inteligentes (Wang, 2011).

A agricultura digital (AD) se torna um caminho para modernização, integração e automação da agricultura e a promove como algo econômico, mecânico, inteligente, de alta qualidade e alto rendimento (Andersen, Jensen \& Skovsgaard, 2016). Porém, mais que digitalizar ou empregar maquinários altamente desenvolvidos, faz-se necessária a implementação de estratégias que agreguem valor ao que é produzido (Luming, 2011; Rogers, 2016).

A agricultura digital é a visão macro da aplicação das tecnologias na agricultura e derivou-se do conceito de Terra Digital na década de 90. Dentre seus desdobramentos, a agricultura Digital começa a se preocupar com o agrupamento cyber físico e chega à Agricultura 4.0. na qual a tecnologia se torna capaz de automatizar os sistemas cyber físico por meio de redes e diferentes máquinas (Weltzien, 2016). Mais que informatização, a agricultura 4.0 passa a abranger a integração das ferramentas, como Internet das coisas, Big Data, e sistemas aos recursos físicos e humanos para que respondam as exigências produtivas do setor e apoiem o seu gerenciamento (Liang, Zhang, Liang, \& Ren, 2002;2003).

A Agricultura 4.0 faz uso de tecnologias inovadoras a fim de modificar a forma como seus processos produtivos são implementados e gerenciados, sendo isso amparado pelo conhecimento que demanda gestão (Diogo, Kolbe Junior \& Santos, 2019). Entretanto, a Agricultura 4.0, em sua grande maioria, ainda se relaciona ao desenvolvimento técnico e tecnológico, com algoritmos e ferramentas que automatizam alguma parte dos processos produtivos (Shamshiri et al., 2018) e é amplamente aplicada como Agricultura Digital. 
Aprofundando nos fatores identificados pelo paradigma da Agricultura moderna, identificouse que o termo agricultura 4.0, ainda recentemente explorado, tem sido utilizado com os mesmos significados da Agricultura Digital. Agricultura Digital e Agricultura 4.0, apesar de possuírem significados distintos, ainda são, consonantemente, expressos e compreendidos de maneira igualitária (Weltzien, 2016).

A mudança desse cenário exige novas visões e estratégias que afetam a cultura da operação de trabalho, as relações humanas e profissionais e os modelos de negócio agrícolas (Vuppalapati, 2017), o que coloca em destaque a Transformação Digital (TD). A Transformação Digital é a possibilidade de estruturação e revitalização dos modelos de negócios para a era digital e propõe diferentes olhares para o que se entrega, a quem se entrega e aos dados que são gerados diariamente (Vaz, APolinario, Correa, Vacari, Gonzales, Drucker, \& Romani, 2017).

Entendimento sobre os dados e produtos agrícolas, conjuntamente com os reais desejos dos clientes e dos envolvidos no negócio, podem ser aplicados às novas soluções de problemas de forma a substanciar inovações na agricultura (Herlitzius, 2017), proporcionando o que se pode chamar de Transformação Agrícola Digital.

Nesse contexto, a Transformação Digital insere-se no contexto da Agricultura Digital mediada pela sociedade do conhecimento, momento em que os processos produtivos aliados a intangibilidade do conhecimento assumem maior relevância que os bens tangíveis. A posição de centralidade assumida pelo conhecimento ancora-se a pilares como capital intelectual e novas estratégias (Stewart, 2002).

Conforme, França, Ziviani \& Muylder (2020, p. 7241): "agricultura é um setor rico em conhecimento que perpassa por caminhos de desenvolvimento e chega a era digital". Aplicar tecnologias que sejam realmente efetivas é o bojo da Transformação Digital e utilizar essas tecnologias para tratamento de informações e conhecimento na agricultura se torna impreterível (Vuppalapati, 2017).

Automatizar mecanismos da agricultura só geram dados para as fazendas. Tratar os dados com austeridade não garante a prática científica ou a aplicação eficiente dos conhecimentos agrônomos. Apesar de se esperar que as tecnologias produzam mais em rendimento, qualidade e sustentabilidade, Shamshiri et al. (2018) afirmam que ainda se tem pesquisas incipientes sobre a tecnologia na agricultura. Algumas explicações se concentram nas complexidades do próprio setor, nos tipos de informações (Shamshiri et al. 2018) e até mesmo na falta de integração dos sistemas digitais (Jayaraman, 2014).

Assim, desenvolve-se essa pesquisa, que tem por objetivo a avaliar, por meio da literatura, a integração das temáticas de Agricultura Digital e Transformação Digital como ferramenta inovadora para o setor agrícola. Busca-se responder a seguinte problemática: qual as relações, advindas de pesquisas cientificas, que medeiam a Transformação Digital e a Agricultura Digital para a inovação do setor agrícola?

Os resultados apontam que a Agricultura Digital tem sido mediada por termos tecnológicos, provocando, muitas vezes, limitações de entendimento sobre a importância da temática Agricultura Digital nos dias atuais. Ao mesmo tempo em que a Transformação Digital traz em seu bojo a premissa de estudos e análises. O termo "processos" promove o vínculo relacional entre ambas as temáticas e serve de alicerce para a integração e promoção da Transformação Agrícola Digital.

A pesquisa está estruturada em seções além desta introdução. A seguir (seção 2) as temáticas Transformação Digital (subseção 2.1) e Agricultura 4.0 (subseção 2.2) são apresentadas. Por conseguinte, tem-se a metodologia (seção 3) e a apresentação e dos resultados (seção 4). Em sequência, as considerações finais são expressas (seção 5), seguidas das referências (seção 6). 


\section{REFERENCIAL TEÓRICO}

\subsection{Agricultura Digital e Agricultura 4.0: o futuro da Agricultura moderna}

Como um meio de subsistência de diferentes regiões, a agricultura passou por diferentes fases e ainda é geradora de riquezas e desenvolvimento econômico. Não há mais barreiras mercadológicas e os países recorrem às especializações e exportações para ganhos de eficiência e apoio aos desafios de produtividade (Bolfe, Victória, Contini, Bayma, Spinelli, \& Gomes, 2016). A informação, a tecnologia e o conhecimento, quando adequadamente utilizados e aplicados, são chaves para o êxito da riqueza econômica e são considerados os recursos tradicionais de trabalho (Vuppalapati, 2017).

Não obstante, esse cenário se desenvolve, mas sem melhoria nos campos produtivos agrícolas não haveria maior visibilidade ao setor. Assim como ocorreu nas indústrias, a Agricultura chega a era digital. A Agricultura Digital é a integração de sistemas científicos (Wang, 2011) com sistemas tecnológicos modernos e novos métodos e abordagens para processar, armazenar e recuperar dados (Jayaraman, Palmer, Zaslavsky, Salehi,, \& Georgakopoulos, 2015).

As tecnologias empregadas elevam o sistema produtivo e torna este setor capaz de atender as novas exigências de mercado (Wang, 2016), ao mesmo tempo que novas práticas da agricultura moderna são aplicadas para gerar grande quantidade de informações (Alencar, Dias \& Francisco, 2017). Os processos agrícolas tornam-se mais gerenciáveis e as operações cotidianas nos campos mais orientadas, produtivas e eficientes. Os trabalhos dos agricultores são pautados na precisão e sustentabilidade (Wang, 2016; Wang et al., 2017). Há intensa competição internacional e a política de protecionismo já não traz mais segurança para as produções (Wang, Balmos, Layton, Noel, Ault,, Krogmeier, \& Buckmaster, 2017).

Ao se estudar a Agricultura moderna, nota-se um desenvolvimento de definições à medida que os anos transcorrem, haja vista que também foram incluídas diferentes ferramentas ao se relatar a agricultura digital. No ano de 2002, Liang et al. (2002) e Tang et al. (2002) concentraram a AD na digitalização e processamento de informações com o objetivo de economia de custos e utilização de recursos e em 2003 o conceito se desdobrou, já tratando a informatização do setor como estratégia de negócios e ganho de vantagem competitiva (Liang et al. 2003).

Novos recursos e modernas férramentas, como sensores de campos, satélites GPS, banco de dados e armazenamento, sistemas inteligentes e de automatização, são incluídos nos conceitos exemplificados a partir de 2010, com Nie et al. (2010), Baozhu e Lei (2011) e Jayaraman et al. (2014), por exemplo. Chega-se as práticas modernas e cyber espaços com a ideia de Shamishiri et al. (2018).

Pode-se apontar alguns apoios técnicos da agricultura digital (Liang et al., 2003, p, 7):

$$
\begin{aligned}
& \text { as tecnologias de máquinas para agricultura inteligente; as tecnologias de coleta em } \\
& \text { tempo real das informações de campo; os sistemas de posicionamento global (GPS); } \\
& \text { os sistemas de informações geográficas (SIGeo); o sensoriamento remoto (RS); a } \\
& \text { tecnologia de gerenciamento de metadados; a tecnologia de rede de computadores de } \\
& \text { banda larga; }
\end{aligned}
$$

Acelera-se a produtividade rural e trabalha a construção de um país voltado para tecnologias limpas e harmoniosas. As distâncias entre os países produtores são reduzidas e se cria um novo conceito de campo (Wang, 2011; Wang, et al., 2017). Nesse novo conceito não existe a separação entre o mundo físico e virtual e aplica-se a Agricultura 4.0, que referencia as ideias da Indústria 4.0 e a construção do espaço cyber físico. 


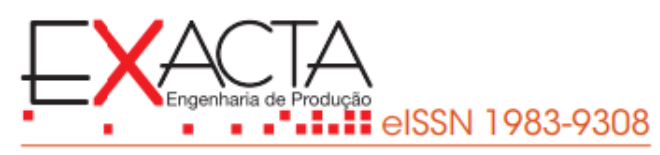

A Agro 4.0 emprega métodos computacionais de alto desempenho, rede de sensores, comunicação máquina para máquina (M2M), conectividade entre dispositivos móveis, computação em nuvem, métodos e soluções analíticas para processar grandes volumes de dados e construir sistemas de suporte a tomada de decisões de manejo. Além disso, contribuirá para elevar os índices de produtividade, da eficiência do uso de insumos, da redução de custos com mão de obra, melhorar a qualidade do trabalho e a segurança dos trabalhadores e diminuir os impactos ao meio ambiente. Engloba a agricultura e pecuária de precisão, a automação e a robótica agrícola, além de técnicas de bigdata e a Internet das Coisas (Massruhá, Leite, 2017, p. 29)

Entretanto, cultivar produtos não é suficiente. É necessário propor ações que visem as exportações de produtos, atendimento ao mercado interno e local, além de atrair investimentos e capitais (Costa, Almeida, Ferreira \& Silva., 2013). É necessário também, adaptar e melhorar os modelos de negócio, atendar a globalização do mercado, as regras de exportação e os desejos dos consumidores, bem como planejar os sistemas de inovação (Antunes, Dias \& Maehler, 2016; Bolfe et al., 2016). Há um cenário de disruptura (Ito \& Howe, 2018) no qual, mais que aplicar a tecnologia, é necessário propiciar uma Transformação Digital uma grande aliada na prática agrícola moderna.

\subsection{Transformação Digital: o complemento Agrícola}

A Transformação Digital pode ser entendida como a junção da tecnologia ao negócio, reestruturando o modus operandi de como os negócios nacionais e mundiais são realizados, comunicados e desenvolvidos (Micic, 2017; Kotarba,2018). Apresenta como resultado a modificação dos modelos de negócios e, por consequência, dos comportamentos sociais e de consumo (Vuppalapati, 2017).

Rogers (2016, p. 18) salienta que a Transformação Digital altera, em sua maioria, "as restrições sob as quais operam praticamente todos os componentes da estratégia de negócios". Por isso, tem-se as visões de que (Rogers, 2016): i) Os clientes são compostos por redes, estão conectados e interagem continuamente, alterando os meios de venda, marketing e força de uma marca; ii) Há uma desintermediação digital no processo competitivo. O que torna as fronteiras setoriais fluidas e os modelos de negócio, muitas vezes, necessitados de parcerias e interdependência para atendimento aos desafios; iii) As interações diversas com o meio interno e externo são capazes de gerar dados que quando tratados deliberam novas fontes de valor. Os dados necessitam ser transformados em ativos que tragam algum benefício para a organização; iv) A inovação, se concentra na realização de experimentos e protótipos de maneira cautelosa e de viabilidade mínima, capaz de gerar aprendizados, redução de risco, custo. É preciso uma dísrupção mercadológica e mais que fabricar produtos, plataformas de negócios devem ser geradas com o objetivo de fornecer novas fontes de criação e entrega de valor; v) A Criação de Valor contempla o estabelecimento do valor que o negócio entrega ao cliente.

Promulga-se que a Transformação digital afete não somente a operação do trabalho, mas a cultura dessa operação, as relações humanas e a velocidade da mudança micro e macroeconômica (Kotarba, 2018), impactando todos os setores da sociedade. Por meio da Transformação Digital emerge oportunidades para um campo agrícola sustentável e para a competitividade rural. Aspectos de inovação, construção de sistemas agrícolas resilientes e com perspectivas bio-econômicas são aspectos chave para o sucesso da Agricultura Digital (Şerbu, 2014).

Mais do que digitalizar os campos e fazendas a união dos aspectos de Transformação Digital e Agricultura Digital permite que as tecnologias sejam empregadas para que se encontre 
soluções de utilização efetiva de recursos escassos, de forma a atender a demanda de consumo global e apoiar a tomada de decisões dos produtores (Guerrieri, Fedrizzi, Antonucci, Pallottino, Sperandio, Pagano, \& Costa, 2017; Navulur, Sastry \& Giri Prasad, 2017). Massruhá e Leite (2017) deixam claro que, o sucesso agrícola dependerá da capacidade e do tempo que se levará para que o produtor compreenda o novo ambiente, consiga se adaptar, intrigar e gerar sistemas dinâmicos e mutáveis que atendam a nova era e as novas exigências.

\section{METODOLOGIA}

Essa é uma pesquisa caracterizada como exploratória descritiva, com abordagem qualitativa para identificar e descrever os fenômenos (existência da conjunção de termos) da realidade (estudos científicos) (Gerhardt; Silveira, 2009). Para realização e efetividade dos resultados da pesquisa, utilizou-se um protocolo de pesquisa adaptado de Dresch, Lacerda, Antunes Jr. (2015) e apresentado no quadro 1 . O objetivo do protocolo foi assegurar a validade e resultado desse estudo. O objetivo do protocolo foi promover uma busca planejada e atinente aos intentos desta pesquisa, bem como permitir sua replicabilidade em momentos futuros. Salienta-se que os fatores Idioma e Ano de publicação dos artigos (análise temporal) não foram limitados para a busca.

Quadro 1 - Protocolo de pesquisa

Fonte: Adaptado de Dresch, Lacerda, Antunes Jr. (2015).

Weltzien (2016) já assinalou que Agricultura Digital e Agricultura 4.0, apesar de possuírem

\begin{tabular}{|c|c|}
\hline Protocolo & Descrição \\
\hline $\begin{array}{l}\text { Ambiente } \\
\text { Conceitual }\end{array}$ & $\begin{array}{l}\text { Transformação Digital: junção da tecnologia ao negócio, reestruturando o modus operandi de como } \\
\text { os negócios nacionais e mundiais são realizados, comunicados e desenvolvidos. } \\
\text { Agricultura Digital: a integração de sistemas científicos com sistemas tecnológicos modernos e novos } \\
\text { métodos e abordagens para processar, armazenar e recuperar dados. }\end{array}$ \\
\hline Contexto & Transformação Digital x Agricultura Digital \\
\hline Tipo de Material & Artigos Científicos \\
\hline Análise temporal & Não se aplica \\
\hline & Indeterminado \\
\hline & E1. Estudos duplicados \\
\hline & E2. Estudos que não apresentem no resumo o(s) descritor(es) de pesquisa e, ou, suas relações \\
\hline & E3. Estudos não disponíveis para download \\
\hline & E4. Estudos que não se enquadrem no ambiente conceitual \\
\hline & $\begin{array}{l}\text { (“Agricultura digital” OR “Digital agriculture” OR "Digital agricultural” OR “Agricultura 4.0” OR } \\
\text { "Agriculture 4.0” OR “Agricultural 4.0”) OR ((“Transformação Digital” OR "Digital } \\
\text { Transformation”) AND (“Agricultura” OR "Agriculture” OR “Agricultural”)) }\end{array}$ \\
\hline & $\begin{array}{l}\text { ("Transformação Digital” OR “Digital Transformation”) AND (“Agricultura 4.0” OR “Agriculture } \\
\text { 4.0” OR “Agricultura Digital” OR "Digital Agriculture”) }\end{array}$ \\
\hline Base de pesquisa & SCOPUS, CAPES e EMBRAPA \\
\hline
\end{tabular}

significados distintos, ainda são, consonantemente, expressos e compreendidos de maneira igualitária. Por isso, tanto o temos Agricultura Digital como Agricultura 4.0 foi utilizado na pesquisa. Anseia-se que os temas relacionados às práticas e aos estudos sobre a Agricultura Digital e a Transformação Digital proporcionem resultados sociais, setoriais e mercadológicos 
positivos. Isso é explorado por meio da análise de estudos presentes nas bases científicas, conforme seção seguinte.

A busca utilizando os descritores expressos no Quadro 1 culminou em 156 artigos científicos, dos quais 115 são pertencentes à base SCOPUS, nove à base CAPES e 32 atinentes à base de periódicos EMBRAPA. A partir disso foram aplicados os critérios de exclusão (vide Apêndice I), sendo identificados 13 estudos em duplicidade (critério de exclusão E1 - Quadro 1), dos quais dois são provenientes da base SCOPUS, cinco da base CAPES e seis da EMBRAPA, culminando na nova monta de 143 artigos.

Em sequência, os resumos foram lidos visando identificar as temáticas Transformação Digital e Agricultura Digital. Do total de 143 artigos o quantitativo de 63 pesquisas - 50 da base SCOPUS, um atinente a base CAPES e 12 da EMBRAPA - não apresentaram no resumo o(s) descritor(es) de pesquisa e, ou, suas relações (critério de exclusão E2 - Quadro 1), culminando em 80 publicações remanescentes. Esse prévio resultado retrata o relato de Bingwen (2005) ao defender a deficiência do desenvolvimento científico na área. Para essè há um excesso de estudos técnicos que relatam apenas algoritmos ou atendem a partições dos setores agrícolas e não a integração, como é verdadeiramente proposto.

Das 80 publicações remanescentes 18 não estavam disponíveis para download (critério de exclusão E3 - Quadro 1), sendo essas desconsideradas de modo a culminar no montante de 62 artigos restantes 1. Esses artigos foram lidos em sua completude, sendo identificados 33 estudos - 25 da base SCOPUS, dois da CAPES e seis da EMBRAPA - que não se enquadraram no ambiente conceitual (critério de exclusão E4 - Quadro 1). À monta resultante, constituída por 29 artigos científicos, foram incluídas três pesquisas consideradas relevantes por serem citadas na amostra descrita e atenderem aos critérios anteriores, culminando na monta final de 33 listados por meio do Quadro 2.

\begin{tabular}{l|l|l}
\hline Base & Autor (es) & Título \\
\hline Capes & Weltzien (2016) & Digital agriculture - or why agriculture 4.0 still offers only modest returns \\
\hline Embrapa & Alencar et al., (2017) & $\begin{array}{l}\text { Agência Embrapa de Informação Tecnológica (Ageitec): avaliação de seus impactos } \\
\text { econômicos. }\end{array}$ \\
\hline Embrapa & $\begin{array}{l}\text { Silva, Zullo Júnior e } \\
\text { Romani (2017) }\end{array}$ & $\begin{array}{l}\text { Active learning e sua aplicação no monitoramento da cana-de-açúcar utilizando o } \\
\text { algoritmo SVM }\end{array}$ \\
\hline Embrapa & $\begin{array}{l}\text { Moura, Barioni,.., } \\
\text { Higa, \& Fasiaben } \\
(2017)\end{array}$ & A prospective study on the application of Data Science in agriculture. \\
\hline Embrapa & $\begin{array}{l}\text { Speranza e Ciferri } \\
(2017)\end{array}$ & $\begin{array}{l}\text { Integração de ferramentas de SIG e mineração de dados para utilização em atividades de } \\
\text { gestão espacialmente diferenciada aplicada na agricultura de precisão }\end{array}$ \\
\hline Embrapa & Vaz et al., (2017) & AgroAPI: criação de valor para a Agricultura Digital por meio de APIs \\
\hline Scopus & Baozhu e Lei (2011) & Probing into application mode of digital agriculture in anhui province. \\
\hline Scopus & Bingwen (2005) & Digital agriculture under the framework of digital province. \\
\hline
\end{tabular}

\footnotetext{
${ }^{1}$ Esses estudos continuaram indisponíveis para download até o desenvolvimento dessa pesquisa e não houve retorno dos autores contatados.
} 


\begin{tabular}{|c|c|c|}
\hline Base & Autor (es) & Título \\
\hline Scopus & $\begin{array}{l}\text { Chen, Wang, Chen, } \\
\text { Zeng, Wang, \& Liu, } \\
\text { (2011) }\end{array}$ & $\begin{array}{l}\text { Research on digital agricultural information resources sharing plan based on cloud } \\
\text { computing }\end{array}$ \\
\hline Scopus & Duan (2010) & Research and analysis about system of digital agriculture based on a network platform \\
\hline Scopus & $\begin{array}{l}\text { Fresco e Ferrari } \\
(2018)\end{array}$ & Enhancing precision agriculture by internet of things and cyber physical systems. \\
\hline Scopus & $\begin{array}{l}\text { Jayaraman et al., } \\
\text { (2015) }\end{array}$ & Addressing information processing needs of digital agriculture with Open IoT platform \\
\hline Scopus & $\begin{array}{l}\text { Liang, Zhang \& } \\
\text { Liang, (2002) }\end{array}$ & The main content, technical support and enforcement strategy of digital agriculture. \\
\hline Scopus & $\begin{array}{l}\text { Liang, Zhang, Liang, } \\
\& \text { Ren (2003) }\end{array}$ & Study on the framework system of digital agriculture \\
\hline Scopus & $\begin{array}{l}\text { Liu, Zhang, Cao \& } \\
\text { Zhu, (2017) }\end{array}$ & $\begin{array}{l}\text { Design and realization of a VRGIS-based digital agricultural region management } \\
\text { system }\end{array}$ \\
\hline Scopus & $\begin{array}{l}\text { Navulur, Sastry e } \\
\text { Giri Prasad (2017) }\end{array}$ & Agricultural Management through Wireless Sensors and Internet of Things \\
\hline Scopus & $\begin{array}{l}\text { Nehra e Nehra } \\
(2005)\end{array}$ & ICT: A new horizon in Indian agriculture. \\
\hline Scopus & $\begin{array}{l}\text { Nie, Wu, Zhang, } \\
\text { Yang, \& He,.(2010) }\end{array}$ & $\begin{array}{l}\text { Hybrid combination of GIS, GPS, WSN and GPRS technology in modern digital } \\
\text { agriculture application }\end{array}$ \\
\hline Scopus & $\begin{array}{l}\text { Rajeswari, } \\
\text { Suthendran e } \\
\text { Rajakumar (2017) }\end{array}$ & $\begin{array}{l}\text { A smart agricultural model by integrating IoT, mobile and cloud-based big data } \\
\text { analytics. }\end{array}$ \\
\hline Scopus & $\begin{array}{l}\text { Shamshiri, Weltzien, } \\
\text { Hameed, Yule, Grift, } \\
\text { Balasundram, \& } \\
\text { Chowdhary, (2018) }\end{array}$ & id development in agricultural robotics: A perspective of digital farming. \\
\hline Scopus & $\begin{array}{l}\text { Shena, Basist e } \\
\text { Howard (2010) }\end{array}$ & Structure of a digital agriculture system and agricultural risks due to climate changes. \\
\hline Scopus & $\begin{array}{l}\text { Shinde, Kimbahune, } \\
\text { Singh, Deshpande, } \\
\text { Piplani, \& } \\
\text { Srinivasan, (2014) }\end{array}$ & mKRISHI BAIF: Digital transformation in livestock services \\
\hline Scopu & $\begin{array}{l}\text { Tang, Zhu, Zhou, Liu } \\
\& \mathrm{Wu},(2002)\end{array}$ & A conception of digital agriculture. \\
\hline Scopus & Wang (2011) & $\begin{array}{l}\text { The effect and development strategies of digital agriculture during new countryside } \\
\text { construction. }\end{array}$ \\
\hline Scopus & $\begin{array}{l}\text { Wang, Balmos, } \\
\text { Layton, Noel, } \\
\text { Krogmeier, } \\
\text { Buckmaster, \& } \\
\text { Ault, (2016) }\end{array}$ & CANdroid: Freeing ISOBUS data and enabling machine data analytics. \\
\hline Scopus & Wang et al., (2017) & $\begin{array}{l}\text { An open-source infrastructure for real-time automatic agricultural machine data } \\
\text { processing. }\end{array}$ \\
\hline
\end{tabular}




\begin{tabular}{l|l|l}
\hline Base & Autor (es) & Título \\
\hline Scopus & $\begin{array}{l}\text { Yang, Wang e } \\
\text { Zhuang (2010) }\end{array}$ & $\begin{array}{l}\text { Case analysis of farm agriculture machinery informatization management network } \\
\text { system }\end{array}$ \\
\hline Scopus & Yao e Wu (2011) & $\begin{array}{l}\text { A research about the application of information technology in the precision agriculture: } \\
\text { Taking the operating system of shanghai agriculture economy as an example }\end{array}$ \\
\hline Scopus & Zhang (2011) & Study about IOT's application in "digital agriculture" construction. \\
\hline Incluído & $\begin{array}{l}\text { Demirkan, Spohrer e } \\
\text { Welser (2016) }\end{array}$ & Digital Innovation and Strategic Transformation \\
\hline Incluído & $\begin{array}{l}\text { Sánchez e Zuntini } \\
\text { (2018) }\end{array}$ & $\begin{array}{l}\text { Organizational readiness for the digital transformation: } \text { a case study research } \\
\text { Incluído }\end{array}$ \\
\hline
\end{tabular}

Quadro 1- Amostra da pesquisa

Fonte: dados da pesquisa

Ratificando o exposto, esses estudos foram analisados em profundidade para levantamento de informações que indiquem o desenvolvimento dessas temáticas, sendo os resultados expressos nas subseções seguintes.

\section{APRESENTAÇÃO DOS RESULADOS}

Essa sessão apresenta os resultados do estudo. Ao analisar os anos das publicações no cenário da Transformação Agrícola Digital é possível identificar a evolução quantitativa de pesquisas que relacionam os termos de Agricultura Digital e Transformação Digital. Observou-se que o início das pesquisas relacionadas as temáticas propostas, têm gênese em 2002. Nota-se, conforme Figura 1, uma maior intensidade a partir de 2010, com destaque para o ano de 2017.

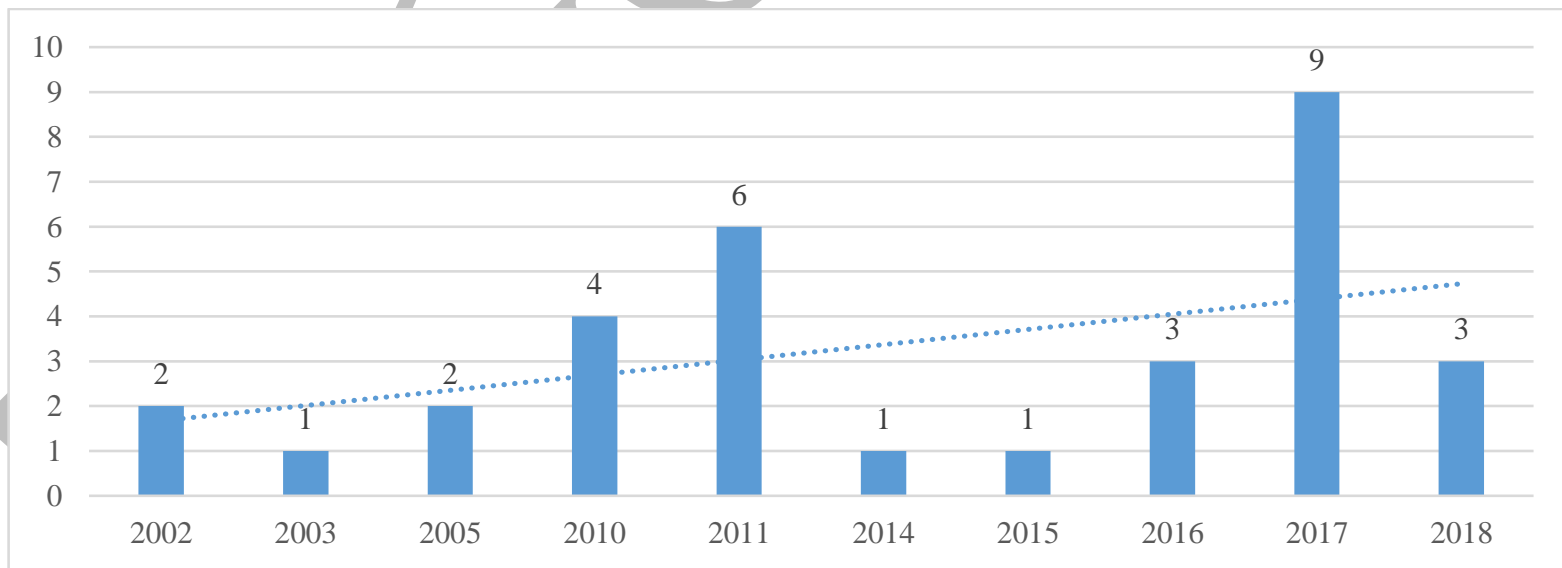

Figura 1 - Relação das publicações por ano Fonte: dados da pesquisa

Houve uma lacuna de publicações entre os anos de 2005 a 2010, perpassando cinco anos sem publicações das temáticas apresentadas. Não foram encontrados fatores que justificassem essa lacuna, mas pode-se inferir que a complexidade e o desenvolvimento dos termos propostos podem influir nas pesquisas. Salienta-se que foi a partir de 2010 a inclusão de ferramentas e recursos mais modernos no conceito de agricultura digital, o que pode impactar nos fatores de 
estudo e desenvolvimento de pesquisa. Ademais, há uma tendência linear de continuidade de pesquisas, o que permite inferir interesse acadêmico nessas temáticas.

Analisando a relação entre os autores, observa-se a formação de redes de autoria. As redes são conjunto de nós e relações que demonstram as interações entre os atores envolvidos. Essas interações são estabelecidas por valores e interesses comuns (Moraes, Furtado \& Tomáel, 2015). As redes formadas por autores são caracterizadas por atores que interagem e buscam o desenvolvimento conjunto e a coprodução em resposta a um problema (Schmid, Knierim \& Knuth, 2016).

Os autores, para essa análise, representam os nós. Os laços que conectam um autor a outro representam as interações existentes, ou a falta delas. A construção científica, nesse contexto, depende da capacidade cognitiva dos atores, da disposição e varia de acordo com a forma de coleta das informações e dos valores individuais e culturais das fontes transmissoras e das fontes receptoras (Boner \& Baumann, 2011; Reiche, 2011). Wang, Y. e Wang, X. são responsáveis por agrupar clusters e manter relações entre autores em busca de resultados para os estudos nas temáticas (Figura 2)
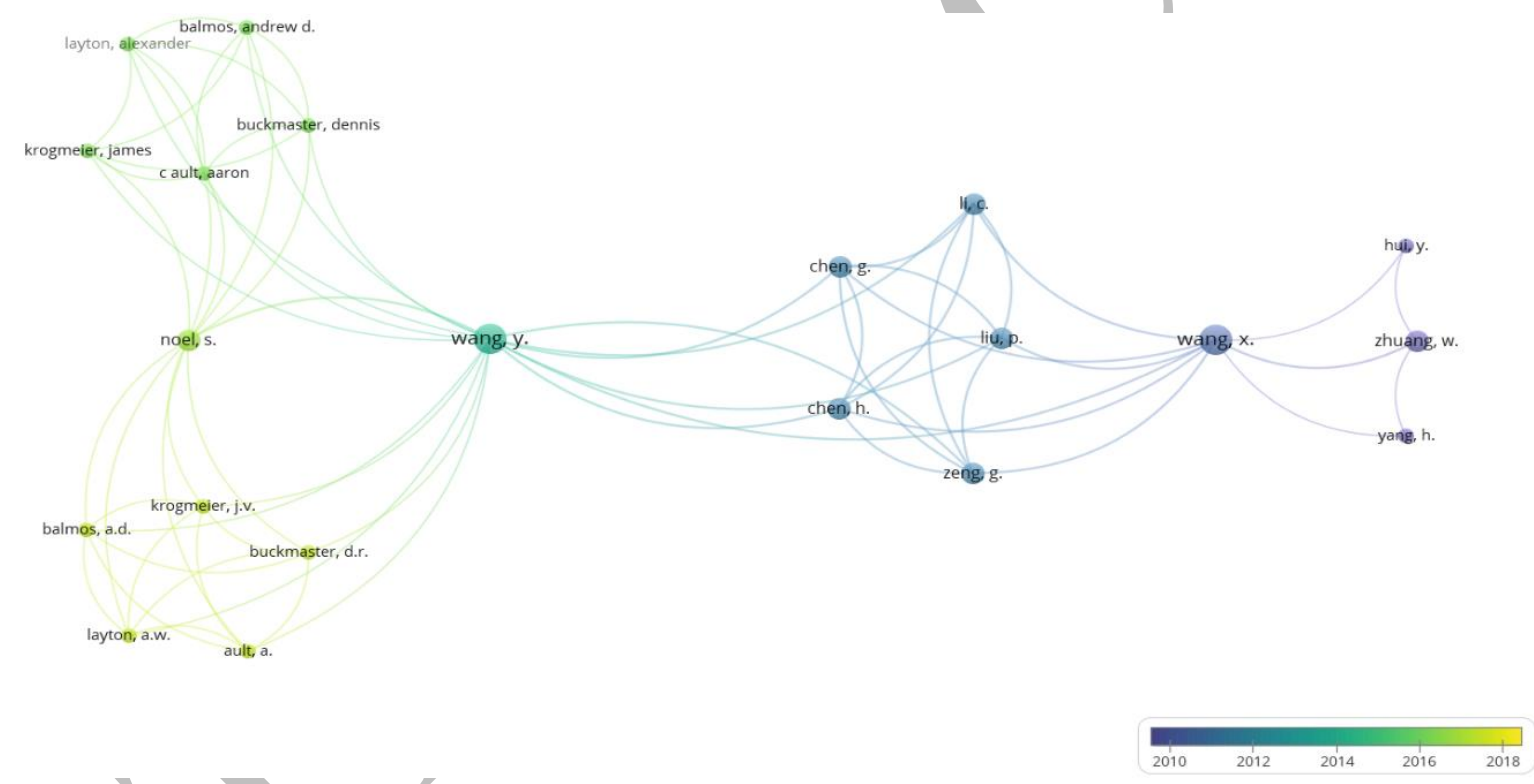

Figura 2 - Relação entre pesquisadores

Fonte: dados da pesquisa

O resultado estabelece a relevância de dois pesquisadores: Wang, Y. e Wang, X. Por meio desses autores, se compartilham ideias, recursos e estimulam os elos da pesquisa científica. Nota-se que as ligações de Wang, X se dá próximo aos anos de 2010 e 2012, incluindo produções com Wang, Y, sendo que esse, por sua vez, cria novos caminhos com ligações a partir de 2012.

Por outra perspectiva, compreende-se a abrangência dos estudos por meio de seus termos. Para isso realizou-se a intercessão de termos contidos nos estudos recuperados, bem como a relação que esses termos apresentam. Como resultado, 92 termos que aparecem mais de duas vezes nos títulos e resumos compõe a rede dos estudos (Figura 3 ). 


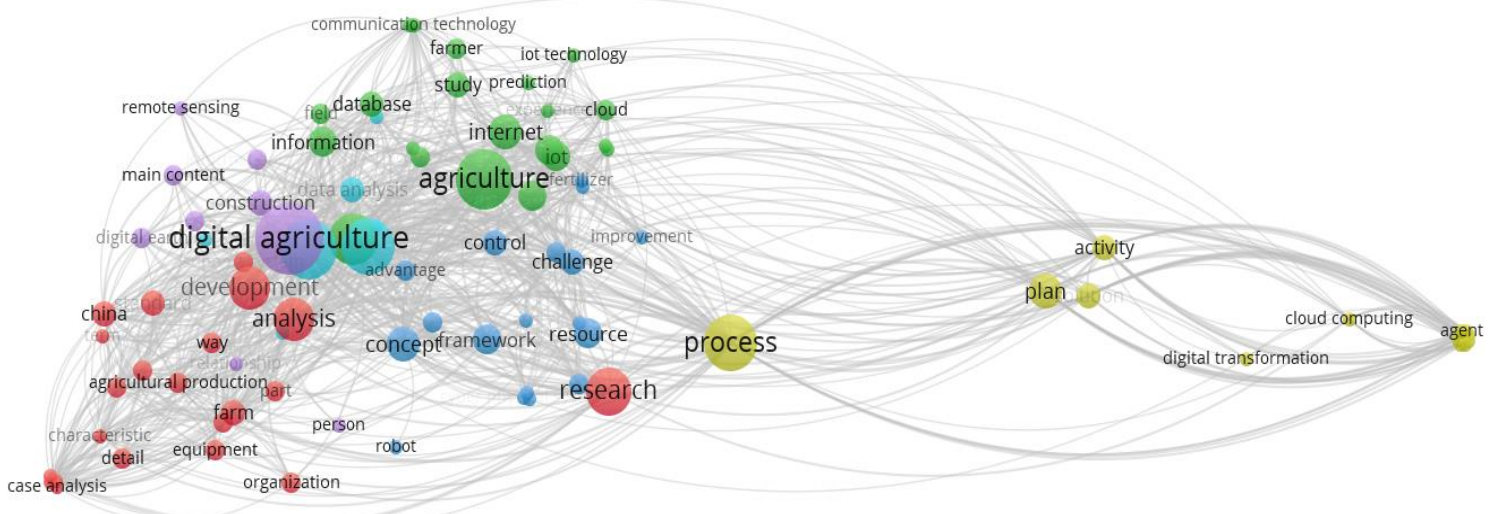

Figura 3 - Relação dos Termos

Fonte: dados da pesquisa

Observa-se que a ocorrência de digital agriculture é relativamente superior a digital transformation, além de ambas apresentarem uma relação distante. O resultado da diferenciação quantitativa já era esperado, haja vista que o número de artigos que contemplam Agricultura Digital é relativamente superior aos estudos sobre Transformação Digital. Além disso, a temática de Transformação Digital ainda é recente e está sendo desenvolvida gradativamente (Rogers, 2016).

Outro ponto relevante está nas conexões realizadas pelas temáticas principais desta pesquisa. A palavra "Agricultura", possui maior número de conexões com outros termos (Figura 4).

Tais termos indicam um desenvolvimento que perpassa relações tecnológicas, como bases de dados, tecnologias de informação e comunicação, sensores remotos, cloud, entre outros, até termos transversais, como planejamento, pesquisas e processos.
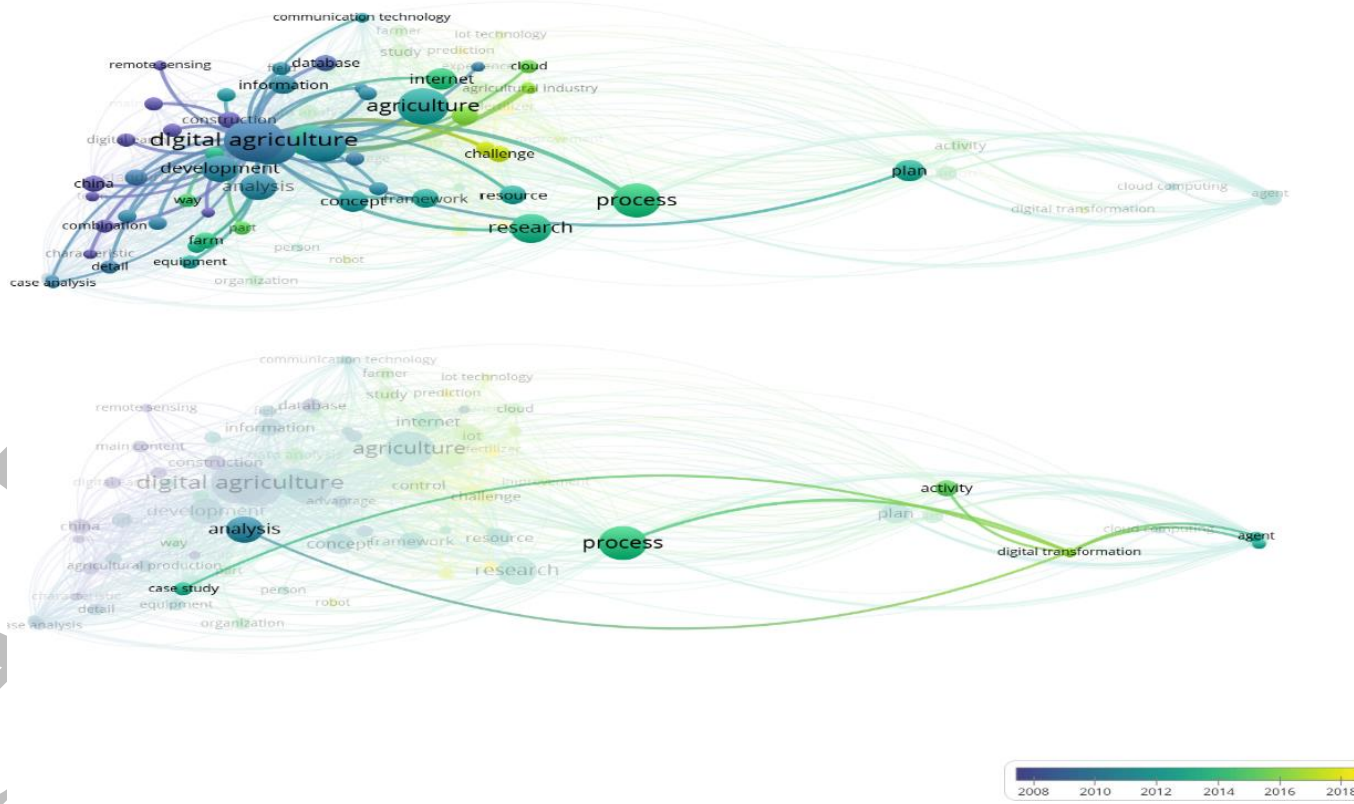

Figura 4 - Conexões individuais dos termos

Fonte: dados da pesquisa 
No ano de 2002, Liang et al. (2002) e Tang et al. (2002) concentraram a Agricultura Digital na digitalização e processamento de informações com o objetivo de economia de custos e utilização de recursos. Os conceitos se desdobram em 2003, já tratando a informatização do setor como estratégia de negócios e ganho de vantagem competitiva (Liang et al., 2003). Novos recursos e modernas ferramentas, como sensores de campos, satélites GPS, banco de dados e armazenamento, sistemas inteligentes e de automatização, são incluídos nos conceitos exemplificados a partir de 2010, como em Nie et al. (2010), Baozhu e Lei (2011) e Jayaraman et al. (2015), por exemplo.

Chega-se as práticas modernas e cyber espaços com a ideia de Shamshiri et al. (2018). Mais que informatização, a Agricultura Digital passa a abranger a integração das ferramentas e sistemas para que respondam as exigências produtivas do setor e apoiem o seu gerenciamento e aqui começa-se o conceito real de Agricultura 4.0, ainda em desenvolvimento.

Nas conexões de Transformação Digital surgem termos mais voltados para planejamento e análise. Aqui se sobressaem termos como processos, análises, estudos e agentes. A tecnologia abre espaço para as relações humanas e para o planejamento. Tem-se então, a Transformação Digital como ferramenta mitigadora das complexidades de desdobramento da Agricultura Digital, oferendo oportunidades para a criação de valor ao cenário agrícola. Vaz et al. (2017) vê a Transformação Digital como um meio de revitalizar os negócios e melhorar a efetividade, sustentabilidade e eficiência por meio de inovações na oferta de produtos e serviços. Surge a oportunidade de se possuir uma produção mais eficiente e novos conceitos para sistemas agrícolas futuros (Herlitzius, 2017).

A complementariedade dos termos se dá por meio da conexão do termo "processos" e logo se avalia a importância da conexão das temáticas para o desempenho agrícola. Os sistemas agrícolas digitais conectam agricultores, gestores e especialistas, independentemente da localidade, criando bases de dados de alta abrangência, de fácil alcance e com gaps de evolução mitigados (Liu et al., 2017; Navulur, Sastry \& Giri Prasad, 2017). Ao mesmo tempo que a integração dos recursos agrícolas modernos à cadeia de valor, proposto pela Transformação Digital, resultam em maior automação, análise de dados e compartilhamento de conhecimento e elevação dos níveis de economia e recursos (Herlitzius, 2017.)

Por fim, a integração da Agricultura digital com a Transformação Digital apresenta a tecnologia como meio do cenário agrícola, fornecendo processos automatizados (Nie et al., 2010), sistemas integrados (Jâyaraman, 2014), mão de obra capacitada (Weltzien, 2016) e aplicação eficaz dos dados (Shamshiri et al., 2018) inteiramente integradas ao negócio e à sua estratégia (Alencar et al., 2017). Condizentes à realidade de cada ambiente, tais recursos e planejamentos direcionam o campo à excelência produtiva.

\section{DISCUSSÃO DOS RESULADOS}

O resultado dessa pesquisa reflete o cenário de inter-relação existente entre os termos Agricultura Digital e Transformação Digital, resultando o que se chama de Transformação Agrícola Digital. Nota-se que com o advento dos recursos tecnológicos propostos pela Era Industrial os espaços rurais puderam ser modificados e as práticas agrícolas automatizas (Andersen, Jensen \& Skovsgard, 2016).

As publicações são recentes e se desenvolvem gradativamente, o que aponta a complexidade de se trabalhar os termos explicitados. Tal resultado também se relaciona ao desenvolvimento 
e melhor acesso das tecnologias pela sociedade, que acabam por provocar estudos e busca de soluções no meio agrícola.

Há um período de maiores publicações e uma discrepância entre o número de publicações dos termos estudados. As maiores publicações ocorrem em 2017 e podem ser justificadas pelas apresentações de Tapscott (2015) quando defende que há uma condição transmoderna e baseada na estrutura de geração do conhecimento aplicável a partir do ano de suas análises. Há um desenvolvimento da agricultura Digital à medida que os anos transcorrem, haja vista que também foram incluídas diferentes ferramentas ao se relatar o setor. Ao mesmo tempo em que se enfatiza a recente discussão sobre a temática Transformação Digital.

A expansão das TICs e sua utilização na agricultura ocorre principalmente pela possibilidade de coleta e processamento de dados originados de diferentes fontes (Koshkarow, 2018) e por isso palavras voltadas para a parte técnica e tecnológica surgem quando se analisa a Agricultura Digital. As buscas de soluções na agricultura são fomentadas e a informação aplicada na solução de um problema concreto.

Nesse cenário, Cowhey e Aronson (2012) apresentam que novos recursos, como disponibilidade de redes de internet de banda larga, integração e armazenamento em escala de informações, junto a nova arquitetura de redes e serviços, crescimento de sistemas de computação virtual para controles de computadores, atendimento a demanda dos usuários e aumento de eficiência, elevam a importância e as pesquisas no setor.

Contudo, as ferramentas empregadas na agricultura devem ser capazes de tonar os processos produtivos mais gerenciáveis e as operações dos campos orientadas, produtivas, eficientes e até mesmo sustentáveis (Wang, 2016; Wang, et al., 2017), com informações confiáveis, precisas e inteligíveis. A captura de grande quantidade de dados e seu armazenamento é complexa e propensa a erros (Chen et al. 2011). Os sistemas são de difícil modificação, difícil integração a outras plataformas e, além de tudo, possuem o desafio de ser interoperáveis (Vaz et al. 2017). Apenas focar no cultivo de produtos não é suficiente para a era digital.

Por isso surge a intercessão da Transformação Digital, que apesar de recente, como se pode ver nos estudos e palavras apresentadas, tem sido amplamente utilizada e debatida nos meios acadêmicos e organizacionais, abrindo espaço para um novo modo de fazer ciência. $\mathrm{Na}$ Transformação Digital, a tecnologia deixa de ser uma parte do setor e passa a ser o centro de todos os processos de negócios, o que pode ser confirmado pela intercessão das palavras Agricultura Digital e Transformação Digital por meio da palavra Processos.

Não se utiliza mais a tecnologia apenas para capturar dados ou para chegar a um objetivo. Utiliza-se as tecnologias para transformar os processos e criar valor com modelos inovadores e ágeis (Demirkan, Spohrer \& Welser, 2016). A tecnologia passa a ser o core operation do negócio. Segundo o World Economic Forum (WEF) (2016) são as tecnologias que transformam as oportunidades de criação de valor de cada organização e que, ao serem agrupadas aos modelos de negócio, fornecem vantagens competitivas incomparáveis. Há uma junção da tecnologia ao negócio, reestruturando o modus operandi de como os negócios são realizados, comunicados e desenvolvidos.

Todavia, mesmo compreendendo todo o conceito e as relações de termos existentes e que originam a Transformação Agrícola Digital, chame-se a atenção para a rede de autoria detectada nesse estudo, que surge por meio da interação entre os autores que publicam sobre 
as temáticas. As redes de autoria no cenário da Transformação Agrícola Digital tendem a revelar a conformação de clusters de pesquisas e pesquisadores profícuos (nós centrais) de dois pesquisadores. A ausência desses pesquisadores provocaria a existência de clusters isolados que não beneficiariam a ciência (Rocha, Costa \& Silva, 2018) e a troca de recursos e conhecimento.

O resultado aponta que ainda se torna necessário um maior envolvimento de autores nas temáticas e o fortalecimento dos laços científicos. A partir da criação de uma identidade coletiva, os atores dessa rede manteriam a sinergia, a colaboração e a reciprocidade durante o processo de transferência do conhecimento e de inovação, facilitando a troca de informações (Lew \& Sinkovics, 2013). Aponta-se então, a singularidade desse tipo de pesquisa e a necessidade de desenvolvimento no cenário mundial, tanto da temática quanto da integração dos pesquisadores.

Conclui-se então, que a Transformação Agrícola Digital é uma oportunidade de compreensão para o novo cenário, no qual manter tecnologias e realizar captura de dados nos limiares das organizações agrícolas são incipientes perante um cenário que exige novas estratégias de gestão e modelos de negócios mais competitivos.

\section{CONCLUSÃO}

A utilização de tecnologias no campo é uma realidade. A Agricultura Digital emprega a utilização efetiva de maquinários, equipamentos e soluções tecnológicas como apoio ao controle e gestão dos produtores. Porém, apenas utilizar tecnologias não é suficiente para efetividade do meio agrícola. A Transformação Digital traz como proposta um novo olhar de mercado que agrupe não só a tecnologia, mas também o desenvolvimento da aplicação dessas tecnologias, cuidado com o cliente, tratamento de dados e entrega de valor. Nesse contexto o conhecimento e sua gestão são elementos que contribuem efetivamente para a promoção dessa transformação.

Essa pesquisa teve como objetivo avaliar, por meio da literatura, a integração das temáticas de Agricultura Digital e Transformação Digital como ferramenta inovadora para o setor agrícola. Identificou-se que os estudos crescem a partir do ano de 2010 de forma inconstante, mas apresentam tendência linear de desenvolvimento gradativo.

Os resultados apontam que a Agricultura Digital tem sido tratada anterior a Transformação Digital e mediada por termos tecnológicos, provocando, muitas vezes, limitações de entendimento sobre a importância da temática Agricultura Digital nos dias atuais. Ao mesmo tempo em que a Transformação Digital traz em seu bojo a premissa de estudos e análises. O termo "processos" promove o vínculo relacional entre ambas as temáticas e serve de alicerce para a integração e promoção da Transformação Agrícola Digital.

Os resultados desses estudos, há contribuições diversas. Para a Teoria, entende-se que a Agricultura Digital deveria inibir os isolamentos de pesquisas científicas relacionadas às indústrias agrícolas e aos seus sistemas digitais, mas ainda há uma lacuna atribuída a estudos voltados para aplicações tecnológicas que atendem a parte específicas das organizações agrícolas. Logo, o estudo busca suprir lacunas e demandas científicas relacionadas ao aprimoramento da Agricultura Digital junto aos fundamentos atuais da Transformação Digital, trazendo conceitos diferentes, mas necessários, de gestão agrícola.

Para a prática o estudo apoia a equidade e a real aplicabilidade da Transformação Agrícola Digital, permitindo que, após compreensão dos conceitos, sejam mitigadas as dificuldades no setor. A apresentação desse estudo abre a reflexão sobre a importância de se preocupar não só 
com a aplicação da tecnologia, mas a importância de manter modelos de negócios e processos eficientes e alinhados. A prática não pode ser longínqua à ciência e a ciência na Agricultura Digital não pode ser tão somente ilustrativa.

Para a sociedade, o estudo permite que, aprimorando os meios agrícolas, o valor possa a ser agregado não só na produção, mas em tudo que envolva o produto e o cliente. Permite que o valor tecnológico sobressaia as porteiras 'da fazenda' e passe a fazer parte de todo o processo da cadeia global e de suprimentos, na qual não só produtores ganham, mas toda a sociedade com elevado poder de barganha e produtos de boa qualidade.

Ademais, compreender o que as temáticas representam e a maneira que intercedem proporcionam ganhos ainda não pensados no meio agrícola. Essa intercessão permite que se extrapole os limiares das organizações agrícolas e agregue valor a todo processo agrícola, não apenas a maquinários ou recursos tecnológicos. Permite também que se compreenda os caminhos percorridos pela pesquisa e a direção que essas estão realizando sobre Agricultura Digital e Transformação Digital.

Esse estudo também fornece informações que apontam uma câminhada para a aplicação da Transformação Digital no cenário Agrícola, sendo essa uma perspectiva que demanda de discussão e pesquisas. Por limitação tem-se o fato desta pesquisa ter sido realizada em três bases específicas. Apesar de grande abrangência e elevada indexação, outras bases podem ser analisadas para o estudo dessas temáticas, sendo essa uma oportunidade de pesquisa futura. Outra proposta futura é a realização de análise dos problemas relacionados à Transformação Digital na Agricultura 4.0, de modo a evidenciar os percalços enfrentados na promoção da Transformação Agrícola Digital ao longo do tempo.

em como o desenvolvimento da conclusão com contribuições para a teoria, prática e sociedade.

\section{REFERÊNCIAS BIBLIOGRÁFICAS}

Alencar, J. R., DIAS, A., Maximo, F. A., \& Francisco, M. S. (2017). Agência Embrapa de Informação Tecnológica (Ageitec): avaliação de seus impactos econômicos. In Embrapa Informática Agropecuária-Artigo em anais de congresso (ALICE). In: CONGRESSO BRASILEIRO DE AGROINFORMÁTICA, 11., 2017, Campinas. Ciência de dados na era da agricultura digital: anais. Campinas: Editora da Unicamp: Embrapa Informática Agropecuária, 2017.

Andersen, T. B., Jensen, P. S., \& Skovsgaard, C. V. (2016). The heavy plow and the agricultural revolution in Medieval Europe. Journal of Development Economics, 118, 133-149.

Antunes, G. M., Dias, M. F. P., \& Maehler, A. E. (2016). Processo de inovação: estudo de caso da adoção do sistema de produção de arroz orgânico vinculada ao NEMA. Revista de Administração da Universidade Federal de Santa Maria, 9(2), 262-279.

Baozhu, S., \& Lei, C. (2011, February). Probing into Application Mode of Digital Agriculture in Anhui Province. In 2011 International Conference on Computer Distributed Control and Intelligent Environmental Monitoring (pp. 2165-2170). IEEE.

Bingwen, Q. (2005, July). Digital agriculture under the framework of digital province. In Proceedings. 2005 IEEE International Geoscience and Remote Sensing Symposium, 2005. IGARSS'05. (Vol. 2, pp. 4-pp). IEEE. 


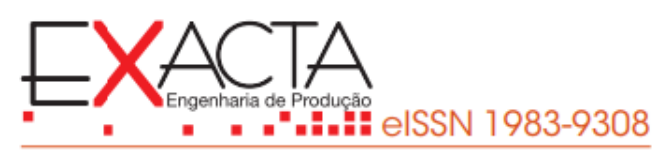

Bolfe, É. L., Victória, D. D. C., Contini, E., Bayma-Silva, G., Spinelli-Araujo, L., \& Gomes, D. (2016). Matopiba em crescimento agrícola Aspectos territoriais e socioeconômicos. Revista de Política Agrícola, 25(4), 38-62.

Bonner, B. L., \& Baumann, M. R. (2012). Leveraging member expertise to improve knowledge transfer and demonstrability in groups. Journal of Personality and Social Psychology, 102(2), 337.

Chen, G., Wang, X., Chen, H., Li, C., Zeng, G., Wang, Y., \& Liu, P. (2011, October). Research on digital agricultural information resources sharing plan based on cloud computing. In International Conference on Computer and Computing Technologies in Agriculture (pp. 346-354). Springer, Berlin, Heidelberg.

Costa, C. C. M., Almeida, A. L. T., Ferreira, M. A. M., \& Silva, E. A. (2013). Determinants of the development of the agricultural sector in municipalities. Revista de Administração, v. 48(2), 295-309..

Cowhey, P. F., \& Aronson, J. D. (2012). Transforming global information and communication markets: The political economy of innovation. MIT Press.

Demirkan, H., Spohrer, J. C., \& Welser, J. J. (2016). Digital innovation and strategic transformation. IT Professional, 18(6), 14-18.

Diogo, R. A., Junior, A. K., \& Santos, N. (2019). A transformação digital e a gestão do conhecimento: contribuições para a melhoria dos processos produtivos e organizacionais. P2p E Inovação, 5(2), 154-175.

Dresch, A., Lacerda, D. P., \& Júnior, J. A. V. A. (2015). Design science research: método de pesquisa para avanço da ciência e tecnologia. Bookman Editora.

Duan, Y. (2010, October). Research and Analysis about System of Digital Agriculture Based on a Network Platform. In International Conference on Computer and Computing Technologies in Agriculture (pp. 274-282). Springer, Berlin, Heidelberg.

França, R.S., Ziviani, F., \& de Muylder, C. F. (2020). Agricultural digitalisation and digital transformation: the future of agricultural competitive excellence in the 4.0 Environment/Digitalização agrícola e transformação digital: o futuro para a excelência competitiva no cenário 4.0. Brazilian Journal of Development, 6(2), 72407260 .

Fresco, R., \& Ferrari, G. (2018). Enhancing precision agriculture by internet of things and cyber physical systems. Atti Soc. Tosc. Sci. Nat. Mem. Supplemento, 125, 53-60.

Gerhardt, T. E., \& Silveira, D. T. (2009). Métodos de pesquisa. Plageder.

Guerrieri, M., Fedrizzi, M., Antonucci, F., Pallottino, F., Sperandio, G., Pagano, M., ... \& Costa, C. (2016). An innovative multivariate tool for fuel consumption and costs estimation of agricultural operations. Spanish journal of agricultural research, 14(4), 4.

Herlitzius, T. (2017). Automation and Robotics-The Trend Towards Cyber Physical Systems in Agriculture Business (No. 2017-01-1932). SAE Technical Paper.

Huntington, S. P. (1994). A terceira onda: a democratização no final do século XX. São Paulo: Ática.

Ito, J., \& Howe, J. (2016). Whiplash: How to survive our faster future. Grand Central Publishing.

Jayaraman, P. P., Palmer, D., Zaslavsky, A., Salehi, A., \& Georgakopoulos, D. (2015). Addressing information processing needs of digital agriculture with OpenIoT platform. In Interoperability and Open-Source Solutions for the Internet of Things (pp. 137-152). Springer, Cham.

Koshkarov, A. V. (2018). Machine learning methods in digital agriculture: Algorithms and cases. International Journal of Advanced Studies, 8(1), 11-26.

Kotarba, M. (2018). Digital transformation of business models. Foundations of Management, 10(1), 123-142.

Lew, Y. K., \& Sinkovics, R. R. (2013). Crossing borders and industry sectors: behavioral governance in strategic alliances and product innovation for competitive advantage. Long Range Planning, 46(1-2), 13-38.

Liang, Y., Lu, X. S., Zhang, D. G., \& Liang, F. (2002). The main content, technical support and enforcement strategy of Digital Agriculture. geo-spatial information science, 5(1), 68-73. 


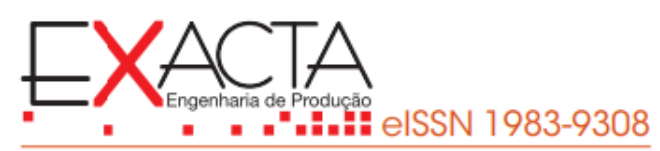

Liang, Y., Lu, X. S., Zhang, D. G., Liang, F., \& Ren, Z. B. (2003). Study on the framework system of digital agriculture. Chinese geographical science, 13(1), 15-19.

Liu, X., Zhang, Y., Cao, W., \& Zhu, Y. (2010, October). Design and realization of a VRGIS-based digital agricultural region management system. In International Conference on Computer and Computing Technologies in Agriculture (pp. 446-455). Springer, Berlin, Heidelberg.

Luming, Y. (2011, February). Regional Digital Agricultural Structure Model Based on Grey-Situation DecisionMaking. In 2011 International Conference on Computer Distributed Control and Intelligent Environmental Monitoring (pp. 565-569). IEEE.

Massruhá, S. M. F. S., \& Leite, M. D. A. (2017). Agro 4.0-rumo à agricultura digital. In Embrapa Informática Agropecuária-Artigo em anais de congresso (ALICE). In: MAGNONI JÚNIOR, L.; STEVENS, D.; SILVA, WTL da; VALE, JMF do; PURINI, SR de M.; MAGNONI, M. da GM; SEBASTIÃO, E.; BRANCO JÚNIOR, G.; ADORNO FILHO, EF; FIGUEIREDO, W. dos S.; SEBASTIÃO, I.(Org.). JC na Escola Ciência, Tecnologia e Sociedade: mobilizar o conhecimento para alimentar o Brasil. 2. ed. São Paulo: Centro Paula Souza, 2017.

Mićić, L. (2017). Digital Transformation and its Influence on GDP. Economics, 5(2), 135-147.

Moraes, M.C., Furtado, R. L., \& Tomaél, M. I. (2015). Redes de Citação: estudo de rede de pesquisadores a partir da competência em informação. Em Questão, 21(2), 181-202.

Navulur, S., \& Prasad, M. G. (2017). Agricultural management through wireless sensors and internet of things. International Journal of Electrical and Computer Engineering, 7(6), 3492.

Nehra, V., \& Nehra, K. (2005). ICT: A new horizon in Indian agriculture. IETE Technical Review, 22(5), 395400 .

Nie, P. C., Wu, D., Zhang, W., Yang, Y., \& He, Y. (2010). Hybrid Combination of GIS, GPS, WSN and GPRS Technology in Modern Digital Agriculture Application. In Advanced Materials Research (Vol. 108, pp. 11581163). Trans Tech Publications Ltd.

Parra, H. C. R. (2007). Economía digital ¿ Se requerien nuevos fundamentos teóricos la definan?. Revista de Administração e Contabilidade da UNISINOS. São Leopoldo, 4(2). 182-191.

Rajeswari, S., Suthendran, K., \& Rajakumar, K. (2017, June). A smart agricultural model by integrating IoT, mobile and cloud-based big data analytics. In 2017 International Conference on Intelligent Computing and Control (I2C2) (pp. 1-5). IEEE.

Reiche, B. S. (2011). Knowledge transfer in multinationals: The role of inpatriates' boundary spanning. Human Resource Management, 50(3), 365-389.

Rocha, M. M. V., da Costa, J. H. L., \& Silva, A. K. A. (2018). A Produção de Conhecimento sobre Regime de Informações nos periódicos em Ciência da Informação. Perspectivas em Gestão \& Conhecimento, (8)3, 255275.

Rogers, D. L. (2016). The digital transformation playbook: Rethink your business for the digital age. Columbia University Press.

Sanchez, M. A., \& Zuntini, J. I. (2018). Organizational readiness for the digital transformation: a case study research. Revista Gestão \& Tecnologia, 18(2), 70-99.

Schmid, J. C., Knierim, A., \& Knuth, U. (2016). Policy-induced innovations networks on climate change adaptation-An ex-post analysis of collaboration success and its influencing factors. Environmental Science \& Policy, 56, 67-79.

Şerbu, R. S. (2014). An Interdisciplinary Approach to the Significance of Digital Economy for Competitiveness in Romanian Rural Area Through E-Agriculture. Procedia Economics and Finance, 16, 13-17. 


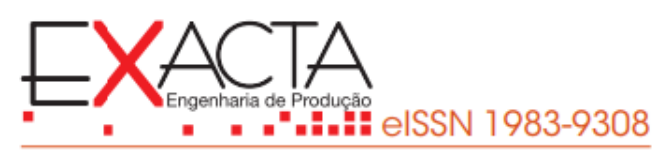

Shamshiri, R., Weltzien, C., Hameed, I. A., J Yule, I., E Grift, T., Balasundram, S. K., ... \& Chowdhary, G. (2018). Research and development in agricultural robotics: A perspective of digital farming.

Shen, S., Basist, A., \& Howard, A. (2010). Structure of a digital agriculture system and agricultural risks due to climate changes. Agriculture and Agricultural Science Procedia, 1, 42-51.

Shinde, S., Kimbahune, S., Singh, D., Deshpande, V., Piplani, D., \& Srinivasan, K. (2014, December). mKRISHI BAIF: Digital transformation in livestock services. In Proceedings of the India HCI 2014 Conference on Human Computer Interaction (pp. 148-153).

Silva, J. P., Zullo Júnior, J., \& Romani, L. A. S. (2017). Active learning e sua aplicação no monitoramento da cana-de-açúcar utilizando o algoritmo SVM. In Embrapa Informática Agropecuária-Artigo em anais de congresso (ALICE). In: CONGRESSO BRASILEIRO DE AGROINFORMÁTICA, 11., 2017, Campinas. Ciência de dados na era da agricultura digital: anais. Campinas: Editora da Unicamp: Embrapa Informática Agropecuária, 2017..

Souza, K. X. S., Ternes, S., Oliveira, S. D. M., Moura, M. F., Barioni, L. G., Higa, R. H., \& FASIABEN, M. (2017). A prospective study on the application of Data Science in agriculture. In Embrapa Informática Agropecuária-Artigo em anais de congresso (ALICE). In: CONGRESSO BRASILEIRO DE

AGROINFORMÁTICA, 11., 2017, Campinas. Ciência de dados na era da agricultura digital: anais. Campinas: Editora da Unicamp: Embrapa Informática Agropecuária, 2017..

Speranza, E. A., \& Ciferri, R. R. (2017). Integração de ferramentas de SIG e mineração de dados para utilização em atividades de gestão espacialmente diferenciada aplicada na agricultura de precisão. In Embrapa Informática Agropecuária-Artigo em anais de congresso (ALICE). In: CONGRESSO BRASILEIRO DE

AGROINFORMÁTICA, 11., 2017, Campinas. Ciência de dados na era da agricultura digital: anais. Campinas: Editora da Unicamp: Embrapa Informática Agropecuária, 2017.

Stewart, T. A. (2002). A riqueza do conhecimento: o capital intelectual ea organização do século XXI. Campus.

Tang, S., Zhu, Q., Zhou, X., Liu, S., \& Wu, M. (2002, June). A conception of digital agriculture. In IEEE International Geoscience and Remote Sensing Symposium (Vol. 5, pp. 3026-3028). IEEE.

Tapscott, D. (2015). The digital economy: Promise and peril in the age of networked intelligence. New York: McGraw-Hill, Special Edition.

Ting, K. C., Abdelzaher, T., Alleyne, A., \& Rodriguez, L. (2011). Information technology and agriculture global challenges and opportunities. Bridge, 41(3), 6-13.

Toffler, A. (1987). A terceira onda. Rio de Janeiro: Record.

Vaz, G. J., APolinario, D. D. F., Correa, J. L., Vacari, I., Gonzales, L. E., Drucker, D. P., ... \& Romani, L. A. S. (2017). AgroAPI: criação de valor para a Agricultura Digital por meio de APIs. In Embrapa Informática Agropecuária-Artigo em anais de congresso (ALICE). In: CONGRESSO BRASILEIRO DE AGROINFORMÁTICA, 11., 2017, Campinas. Ciência de dados na era da agricultura digital: anais. Campinas: Editora da Unicamp: Embrapa Informática Agropecuária, 2017.

Vuppalapati, J. S., Kedari, S., Ilapakurthy, A., Ilapakurti, A., \& Vuppalapati, C. (2017, April). Smart DairiesEnablement of Smart City at Gross Root Level. In 2017 IEEE Third International Conference on Big Data Computing Service and Applications (BigDataService) (pp. 118-123). IEEE.

Zhang, W. (2011, September). Study about IOT's application in" digital Agriculture" construction. In 2011 International Conference on Electrical and Control Engineering (pp. 2578-2581). IEEE.

Wang, S. W. (2011, August). The Effect and Development Strategies of Digital Agriculture during New Countryside Construction. In 2011 Second International Conference on Digital Manufacturing \& Automation (pp. 1270-1273). IEEE. 
Wang, Y., Balmos, A. D., Layton, A. W., Noel, S., Krogmeier, J. V., Buckmaster, D. R., \& Ault, A. C. (2016). CANdroid: Freeing ISOBUS Data and Enabling Machine Data Analytics. In 2016 ASABE Annual International Meeting (p. 1). American Society of Agricultural and Biological Engineers.

Wang, Y., Balmos, A. D., Layton, A. W., Noel, S., Ault, A., Krogmeier, J. V., \& Buckmaster, D. R. (2017). An Open-Source Infrastructure for Real-Time Automatic Agricultural Machine Data Processing. In 2017 ASABE Annual International Meeting (p. 1). American Society of Agricultural and Biological Engineers.

Weltzien, C. (2016). Digital agriculture or why agriculture 4.0 still offers only modest returns. Landtechnik, 71(2), 66-68.

WEF- World Economic Forum White Paper Digital Transformation of Industries: Digital Enterprise. Digital Enterprise. January, 2016. Disponível em: http://reports.weforum.org/digital-transformation/wpcontent/blogs.dir/94/mp/files/pages/files/digital-enterprise-narrativefinal-january-2016.pdf. Acesso em: $01 \mathrm{de}$ Fevereiro de 2021.

Yang, H., Wang, X., \& Zhuang, W. (2009, October). Case Analysis of Farm Agriculture machinery informatization management network system. In International Conference on Computer and Computing Technologies in Agriculture (pp. 65-76). Springer, Berlin, Heidelberg.

Yao, H., \& Wu, Y. X. (2011, October). A Research about the Application of Information Technology in the Precision Agriculture: Taking the Operating System of Shanghai Agriculture Economy as an Example. In International Conference on Computer and Computing Technologies in Agriculture (pp. 215-223). Springer, Berlin, Heidelberg.

\section{APÊNDICE I}

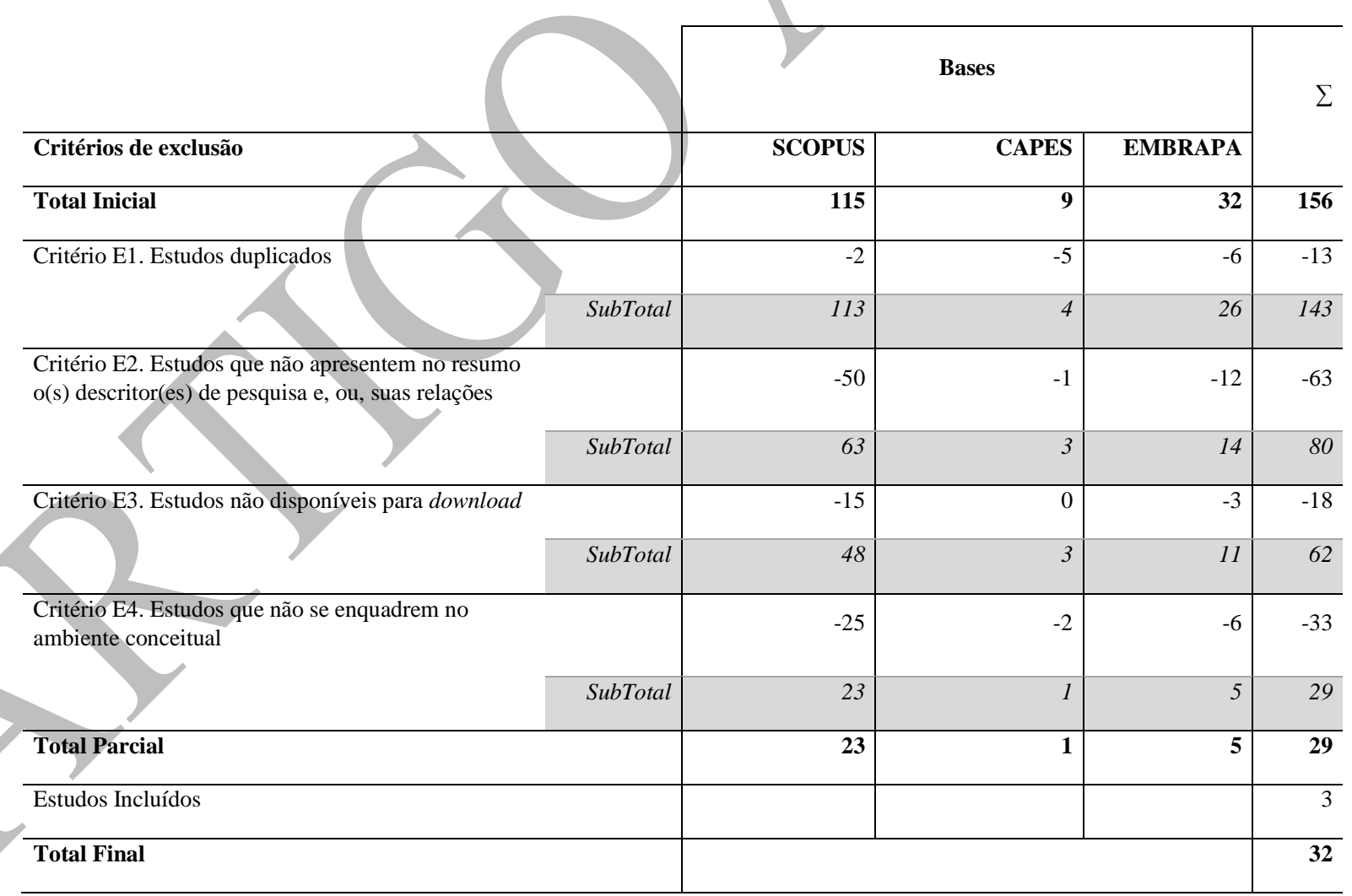

Quadro 3 - Aplicação do protocolo de pesquisa

Fonte: Dados da pesquisa. 